\title{
Psychological Features of Socialization of the Young Generation in the Conditions of Post-Conflict Society
}

\author{
Olga Moskalenko ${ }^{1}$, Larisa Khabaeva ${ }^{2},{ }^{*}$ Inna Abaeva ${ }^{3}$, Elena Gioeva ${ }^{4}$, Elena \\ Siukaeva ${ }^{5}$
}

\author{
1 Moscow Pedagogical State University, Institute of world civilization, Russia \\ ${ }^{2}$ Vladikavkaz Institute of Management, Russia \\ ${ }^{3}$ North Ossetian State Pedagogical Institute, Russia \\ ${ }^{4}$ Center for Social and Psychological Research LLC, Russia \\ ${ }^{5}$ South Ossetian State University, Republic of South Ossetia \\ *Email: haba-eva@yandex.ru
}

\begin{abstract}
The article is devoted to identifying and substantiating the psychological characteristics of the socialization of the younger generation in a post-conflict society. The relevance of the study lies in the fact that in the modern world the number of regional conflicts is growing, despite all the warnings from international organizations and leaders of movements for the struggle for a culture of peace. Regional conflicts are often protracted and long-term, they affect the material and moral resources of the region's ethnic groups, thereby causing irreparable harm to the region and the whole world. The purpose of this article is to describe the psychological characteristics of the socialization of the younger generation in a post-conflict society. The objectives of the research are - to analyze the ethnic conflict from the standpoint of psychology and to identify the psychological characteristics of the socialization of youth in a post-conflict society. The research methods were theoretical comparative analysis of psychological sources and included observation of the population in a situation of ethnic conflict and after it (1990-2020). The results of the study were theoretical conclusions about understanding the socialization of the younger generation as gaining experience in overcoming the consequences of ethnopolitical conflict and the psychological characteristics of this socialization. The specific features included: understanding and awareness by the young generation of the impossibility of a military adjustment of an ethnopolitical conflict and the only way to resolve it - to implement a peaceful solution of the conflict; assimilation of knowledge about the genesis of both the conflict situation itself and the subjects of the conflict and the countries, peoples, surrounding this conflict, etc .; creation of conditions for the entogenesis of each nation, which is part of the national composition of the country, and understanding of its role in a multinational state; the presence of authoritative leaders ("Father of the Nation") and their advisers, or persons close to the leader; taking into account various ethnosocial and ethnopsychological characteristics of a people, nation or ethnos; determination of the "strength" of the ethnic in the self-consciousness of the people; the impossibility and inadmissibility of the "transfer" of the regional conflict by the young generation to another territory, another region and at another time; inadmissibility of covering future generations in a conflict situation. The results include practical recommendations for building further socio-psychological work to socialize the young generation in a post-conflict society. Research prospects are presented in the development of a sociopsychological program for specific regions and the identification of mechanisms and patterns of socialization of the young generation in a post-conflict society in the 21 st century.
\end{abstract}

Keywords: Socialization, Post-conflict society, Youth, ethno-political conflict, Experience of overcoming the consequences of the conflict. 


\section{INTRODUCTION}

The process of socialization of the younger generation in all countries and at all times is rather complicated and ambiguous. The problem of generation gap, an informal and contradictory attitude to attempts at formalization by the state and the family in the form of teachers' demands, parental prohibitions, condemnation of the older generation acted as rebelliousness of young people, which had positive and negative psychological consequences for the individual. The first include: solving the issue of finding oneself, personal and professional self-determination, self-understanding of life orientations and value attitudes, conscious generation and establishment of ways to achieve them, development of self-awareness and construction of a life path. The negative in this rebellion is considered to be: mental damage (not solving the problems of growing up or traumatic exits from age crises) and physical health (mass fights, addictive, antisocial and self-destructive behavior, promiscuous sexual relations), the destruction of interpersonal relationships in society.

A completely different picture of the socialization of the younger generation manifests itself in a situation of conflict in society or after its solving on a temporary or permanent basis.

In a post-conflict situation, the younger generation sets, first of all, the task of physical and mental survival, and only then - the search of oneself, self-determination and self-understanding. The paradox of the situation lies in the fact that despite the mental and physical experiences, especially in the military phase of the conflict, the younger generation faces the problems of their socialization and tries to solve them in this difficult situation for any person.

The research methods were theoretical comparative analysis of psychological sources and included observation of the population in a situation of ethnic conflict and after it (1990-2020).

\section{METHODOLOGY}

The methodology for studying the psychological characteristics of youth socialization in a post-conflict society was based on two approaches. The first approach is a general scientific approach to the study of conflict. The second is a psychological analysis of the conflict.

\subsection{General scientific study of conflict}

Within the first approach, a conflict (lat. Conflictus) is understood as "a collision of oppositely directed, incompatible with each other tendencies in the consciousness of a single individual, in interpersonal interactions or interpersonal relations of individuals or groups of people, associated with acute negative emotional experiences" [1, C .60].
There are several approaches to understanding conflict:

- the existence of contradictions and conflicts of ideas, the leading source of political struggle (A. Bentley, K. Boulding, G. Simmel, L. Coser, K. Marx, A. Tocqueville [2, p.18]);

- the conflict in understanding the essence of politics is secondary, it obeys the main social norms and priorities that unite society and integrate it from the standpoint of a certain political structure (M. Veber, V.I. Blischenko, M.M. Solntseva [3, p. 27])

The definition of the conflict determines its causes as contradictions that cannot be resolved, on the one hand, in a short period of time - "here and now", and on the other - meaningfully - the abnormality of relations, politics, violation of any process.

There are multifaceted and multivariate classifications of conflicts according to:

- maturity, type and urgency of resolution;

- tendencies of resolution;

- zones and areas of manifestation of conflicts foreign and internal political conflicts, which have various subspecies according to the types of crises and contradictions;

- the degree and nature of the normative regulation of conflicts;

- qualitative characteristics that reflect the different level of involvement of the parties to the conflict, the tension and intensity of the crisis and disagreement;

- time indicators: long-term (continuous, year-term, decade-term) and short-term (resolving in the shortest period);

- government conflicts, distinguished by the desire to organize the state system[4, p.24], [5, p. 21].

The types of conflicts are differentiated on various grounds: adaptation, military, armed, latent, moral, ergatic [6, p.16]; violent (antagonistic), compromise, political, social, economic; interethnic, ethnic, ethnopolitical, ethnoterritorial, regional [Ibid., p.28].

Conflicts in the North Caucasus are especially differentiated as: conflicts related to cross rights to resources, primarily to land; conflicts associated with the monopolization of rent, the overlap of "vertical elevators" and the impossibility of building career strategies based on merits and qualifications [Ibid, p.70].

To solve the problems of our research, we will study the features of some types of conflicts. An interethnic conflict reveals contradictions at the socially conscious level that appear in the process of dissatisfaction with the attitude of one people to another. This conflict is 
distinguished by confrontation and activates its relationship. This conflict plays the role of a real political event, demonstrates the influence of the national movement [7, p.36].

Ethnic conflict is of interest as a particular form of international conflict. The peculiarities of the opposing subjects of the conflict sanction the following conflicts: "horizontal" - as a conflict between ethnic groups and ethnic groups and "vertical" - a conflict between an ethnic group and the state [Ibid., p.38].

When defining an ethnic conflict, the actions of the conflicting parties are analyzed and the following characteristic features of this type of conflict are identified:

- ethno-selective outcomes and mass migrations from the region, while the ethno-demographic balance of a country or region is changing;

- the creation of political organizations in the form of movements ("national", "cultural"), parties that declare their need to change the current situation of an ethnic group (groups), thereby provoking the authorities to respond, and also mobilize other local ethnic groups who do not agree with their position to defend their rights;

- spontaneous actions of disagreement with limiting the interests of some in favor of other local ethnic groups, with decisions of state authorities in various forms (rallies, processions, riots).

In an ethnic conflict, there is a social situation in society, which is dictated by the following contradictory circumstances:

- mismatch of interests and goals of one or several ethnic groups within the boundaries of a single space, on the one hand, and the state, on the other;

- at the intersection of ethnic and political space, the interests and goals of a particular ethnic group are manifested in the desire to transform the existing ethnic inequalities or political space in its territorial dimension [4, p.25].

Ethno-territorial conflicts are distinguished [6, p.20].

The following features of "new generation conflicts" (conflicts of the late XX - early XXI centuries By P.A. Tsygankov [1, p.67]) are highlighted:

- the causes and sources of conflicts, participants in conflicts have changed, therefore these are "identity conflicts" (M.M. Lebedeva [6, p.89]) (since they are associated with the problem of self-identification);

- "new fighters" appear, whose motives are lack of interest in ending the conflict, since after the end of the conflict society often cannot offer them attractive incentives to engage in constructive work;
- the nature and content of conflicts is changing (less interstate, more - intrastate or regional);

- a large number of refugees appear (V.A. Moskalenko [7, p.34].

The transition of the content and nature of interstate conflicts into regional ones in form and geography, while in terms of content and subjects, these are ethnopolitical conflicts.

In modern conflicts, there are contradictions between the following subjects: individual states, their blocs and allies, associations, coalitions, or individual subjects of social interaction within the state. Substantial geographic and social spaces are becoming the arena of conflict. The methods of implementation and solution of the conflict are diplomatic negotiations with the help of a third party, or armed intervention [4, pp.25-26].

The peculiarities of modern conflicts are their regionality, which is expressed in the following: they are interconnected and interdependent on global ones and also have their source of contradictions (economic, political, ethnic, religious and ideological).

The following characteristics of modern regional conflicts can be distinguished:

- a complex form of conflict - long-term, rapid or hybrid clashes (as a rule, national-ethnic and religious);

- a protracted nature due to the high complexity of resolving conflicts, which suited all parties to the conflict;

- close influence on the world system of international relations;

- different composition of subjects, actors (ethnic group, administrative-territorial entity, state or block of states, their association, political, economic and national elite, etc.), as well as third parties - allies, leading players in the region, etc.;

- differences in conflict expansion zones is the coverage of various parts (including large ones) of geographic spaces (regions), and, accordingly, a significant number of people;

- genesis and dynamics of the conflict;

- hybridity of the conflict - conflict on the fields of the media, on the Internet and social networks, speeches and propaganda in different countries and on the platforms of international institutions and organizations, conferences, manifestations and demonstrations in several countries and other means and methods of information, economic and political wars;

- forms of open conflict confrontation: war, armed conflict, economic sanctions, ideological confrontation, etc. (V.A. Moskalenko [5, p.45]; F. Charton-Vachet, C. Lombart [8, p.58]). 
Regional conflicts are classified according to the following indicators:

- The scale of the conflict: interstate, inter-bloc, intercoalition, etc.; intrastate, intersubjective - between the actors of society within the state.

- Features of the situation of the conflict in terms of geography: Asia; Africa; Latin America; Europe.

- Sphere of manifestation of the conflict: economy; politics; spiritual and ideological sphere (religion, culture, etc.); military sphere.

- National and ethnic characteristics as a basis for the emergence of a conflict: ethnos and ethnic characteristics; ethnopolitical differences; religion and its various directions (V.A. Moskalenko [5, p. 47], Shale Horowitz [9, p.640]).

One of the most costly conflicts resource is a regional armed conflict, or regional war, which is understood as a limited conflict that has unresolved regional conflicts as its cause. This conflict is localized within the region, while its economic, political, territorial, confessional and other consequences can affect other countries and regions. It can take the direct (in the form of private military campaigns, military assistance, volunteers) and indirect (in the form of supplying weapons, organizing the work of advisers) participation of countries that not only do not belong to this region, but are also located on another continent [5, p.67].

The following prerequisites for regional conflicts are revealed [6, p.54]: socio-economic; cultural and linguistic; territorial status; separatist.

One of the essential features of modern regional conflicts of the XXI century, which have a history from the XX century and some even longer, with a change in the localization of the conflict, a decrease in the territory involved in the conflict, is the increase in the international significance of their resonance from this conflict around the world through the virtual environment, the Internet space, media and social networks. International significance is also increasing due to the appearance of a large number of refugees in other countries, as well as the involvement of many states and international organizations in their adjustment.

Thus, the main characteristics of regional conflicts are: controllability; politicy or military-politicy; localization; burden by external interference; the presence of external forces and the nature of their impact on the subjects of the conflict; the presence and differentiation of internal forces on moderate and radical, the nature of their impact; the correlation of armed forces, the possibility of mobilization, potentials and resources of military and other assistance from others; peculiarities of national psychology (endurance, sacrifice, suffering, level of organization) [5,7].
These characteristics allow us to give a psychological analysis of the conflict and its consequences for a person.

\subsection{Psychological analysis of the conflict}

We will start the psychological analysis of conflict and conflict situations with the subjects of the conflict. They are understood as two or more actors, the main interests of resolving the situation for the benefit. Each subject of the conflict has a conscious or unconscious conflict strategy (T. Schelling [10, p.17]), which should lead to a win for the interested party. Also, the conflict strategy allows for the presence of not only opposite or conflicting motivations of the actors in the conflict, but also of any common interests, for example, bringing to a logical end and determining the independent status quo of a territory, a separate part of a country or state.

It is psychologically important to determine the "strength" of the subject of the conflict. In our understanding, when considering an ethnopolitical conflict, strength is understood as its: economic and geographical position, historical experience, peculiarities of the national character, stability of the state system, the existence of contradictions within the country, positive characteristics of negotiations, the presence of communication and support of the country's leaders with the population. In "strength" is the potential of the subject of the conflict to achieve their goals (E.N. Ryadinskaya [11, p.199]).

In this aspect, it is important to note the vector of analysis of the socio-psychological analysis of the group as a subject of conflict (I.A. Alikin, M.I. Alikin, N.V Lukyanchenko [12, p.78], L.M. Mitina, G.V. Mitin [13, p.93], M. Antonsich, E. Holland [14, p.209], C. Zuniga, R. Asun [15, p.220]. In this case, the following components of the analysis are important:

- content, conditions, uniqueness and nature of the group's activities; competition within and outside the group; number of group members; mechanism for joining the group;

- level of group development: differentiation of power and functions in the group; identification of the structure and state of interpersonal relationships;

- system of motivation, uniting members of the group or not; features of the motivation of group members;

- the intensity and frequency of contacts of group members with each other and with opponents, representatives of other groups as an indicator of the group's independence;

- essential personal characteristics of group members, formal and informal leaders, analysis of decision making and delegation of authority from management structures to subordinates. 
The second aspect in the psychological analysis of the conflict is the true interests and goals of the parties to the conflict, the contradictory nature of these interests and goals, the reasons and meaning of the conflict. The failure of a positive resolution of the conflict is determined by the impossibility of an adequate and complete identification of the true goals and interests of the subjects of the conflict or third forces [2, p.8]. It is the true interests and goals of the parties to the conflict that will make it possible to identify the cause and subject of the conflict (L.V. Luchsheva [16, p.207]).

The subject in an ethnopolitical conflict can be: territory, political and economic resources, status and values [4, p.23]. When analyzing the interests and goals of the subjects of the conflict, it is important to identify the contexts (social, domestic, international and political (Ibid.: 24) and the fears of the subjects of the conflict, which may have a deterrent effect of resolving the conflict. The synonymous row "cause of the conflict", "source of conflict", "nature of the conflict", "roots of the conflict" is used to understand the determination of the conflict. By "interests" we mean the goals of the subjects of the conflict or third forces, by "position" - the process of formulating the interests of the subjects of the conflict or third forces (A.A. Sultygov [17, p.72].

The third aspect of the psychological analysis of the conflict - the conflict itself, its type, phase, dynamics and genesis, the nature of violations of communication between the parties to the conflict in the process of its existence is also connected with it. It is important to consider the conflict within the framework of conflict genesis [5, p.777], which changes concern the parties to the conflict, their goals and the subject of the conflict, as well as to analyze the activities of the parties to the conflict and third forces in the process of conflict development.

The fourth aspect of the psychological analysis of the conflict is to single out the "proper psychological" nature of the conflict, which will allow us to better understand the "psychology" of the subjects of the conflict. This includes:

- description of the emerging social situation, conflict,

- social events preceding the onset of a conflict;

- demonstration of the age and individual characteristics of the subjects of the conflict in their conflict behavior;

- description of the situation "through the eyes of opposite" parties;

- the social and personal position of each subject in the conflict in relation to each other;

- proposals of the parties to the conflict on the cancelation, prevention and resolution of the conflict both at present and in the future, as well as their assessment (N.M. Borisova, I.V. Shapovalenko [18, p.120], V.V. Bartsalkina, L.V. Volkova, I. Yu. Kulagin [19, p.73]. E.G. Siukaeva, L.M. Khabaeva, M.Z. Gazzaeva, N.M. Gazzaeva, I.V. Abaeva, E.P. Gioeva [20, p.11] O. Ghimbulut, A. Opre [21, p.311], K. Homa [22, p.16]).

A psychological analysis of the ethnopolitical conflict will allow us to identify the psychological characteristics of the socialization of the younger generation in a postconflict society.

\section{RESULTS AND DISCUSSION}

In a post-conflict society, the socialization of the younger generation takes place in the acquisition of social and personal experience by young people in overcoming the consequences of an ethnopolitical conflict and obtaining objective and subjective results. The first include noticeable modifications in the social status of a young person, which depend on the new social roles one has mastered and are associated with new social experience. One of the important subjective results of socialization is the development of self-awareness and identity of a young person in various aspects - personal, group, cultural, ethnic, national, corporate, religious, civic, etc. An ethnic identity, which acts as self-identity with one's ethnic group, forms in a young person in the situation of ethnopolitical conflict and further in the state of post-conflict society.

Therefore, the first feature of the socialization of the younger generation as gaining experience in overcoming the consequences of an ethnopolitical conflict can be defined as the understanding and awareness by the young generation of the impossibility of a military solution of an ethnopolitical conflict, while the only way to resolve it is the implementation of a peaceful resopution of the conflict. Ethnopolitical conflict has different dynamics of its course - phases of acute exacerbation and attenuation. However, almost all the peoples of the world come to the priority of the idea of a peaceful adjustment when choosing a solution to the conflict. Moreover, the progressive world forces and most of the global powers also give preference to a culture of peace and harmony, rather than military action in resolving conflicts in any region of the world. Examples are conflicts in the Middle East, North Africa and Central Asia: in the second half of the twentieth century (Korea, 1953; Nagorno-Karabakh, 1987-1991; Kosovo, 1992-1999 and the Bosnian war 1992-1995; Palestinian-Israeli conflict, Iran - the Iraqi war, the war in the Persian Gulf zone, the Iraqi-Kuwait conflict) and the 2000s-10s of the XXI century (Afghanistan, Abkhazia, 2000-2010, the events of the Arab Spring, as well as armed conflicts in Iraq and Syria) (V.A. Moskalenko [5, 7]). 
The second feature of the socialization of the younger generation in gaining experience in overcoming the consequences of an ethnopolitical conflict can be defined as the assimilation of knowledge about the genesis of both the conflict situation itself and the subjects of the conflict and the countries, peoples countries surrounding this conflict, etc. An example can be some European countries, which formed a modern system for the peaceful solution of international disputes within the panEuropean process. It has been formed through regular meetings of representatives of the CSCE member states (special meetings of CSCE experts on the peaceful solution of disputes (Montreux - 1978, Athens - 1984, Valletta - 1991, Geneva - 1992)). Therefore, the young generation of the EU, accustomed to the peaceful resolution of any conflict through negotiations and consideration of compromises, was not ready for conflicts and aggressive behavior of representatives of other ethnic groups at the beginning of the 21 st century with an influx of refugees from the Middle East and Africa (M.M. Lebedeva [6, p.116], S.R. Maddi, D.M. Khoshaba [23, p.270], E. Schubach, J. Zimmermann, P. Noack et al. [24, p.191]).

The second example of the socialization of youth as gaining experience in overcoming the consequences of an ethnopolitical conflict through the assimilation of knowledge about conflict genesis can be an active scientific and practical development of the problem of resolving any conflicts in research centers and foreign and domestic scientific literature The Journal of Conflict Resolution, The International Journal of Conflict Management, Journal of Peace Research, Negotiation Journal, International Negotiation: A Journal of Practical and Theoretical Research. This scientific literature develops the methodological and conceptual apparatus of the problematics of the conflict and itssolution. (A.A. Sultygov [17, p. 78]).

The third feature of the socialization of the younger generation as gaining experience in overcoming the consequences of an ethnopolitical conflict is the creation of conditions for the entogenesis of each nation, which is part of the national composition of the country, and an understanding of its role in a multinational state. An example of the genesis of ethnic consciousness of peoples can be, on the one hand, the awareness of their place as a national minority in the country, and on the other, the creation of an ethnic culture of the importance of each people in the country, respect for the traditions and culture of ethnic groups, the preservation of the native language for an ethnic group, people, nationality, regardless of the number of their representatives. National minorities appeared in different countries for several reasons: the impossibility of creating their own state (Basques, Bretons, Slovaks, Silesians); dynamics of state borders (Hungarians in Romania, Belarusians in Poland, Austrians in Italy); massive economic (labor) or political migrations (Turks in Germany, Algerians in
France, Poles in Great Britain, Germany). It is important to note that these national minorities, understanding their role in this country, do not conflict with the main ethnic group of the country (L.A. Maksimova, R.A. Valiev, N.B. Ruzhentseva, T.V. Valieva [25, p.88], O.E. Khukhlaev, V.M. Minazova, O.S. Pavlova, E.V. Zykov $[26$, p.34]).

An example is the national policy in the Russian Federation, which is based on the "Law on the Languages of the Peoples of the Russian Federation" (No. 1807-1 of 25.10.1991, as amended. Federal Laws of July 24, 1998 No. 126-FL, of December 11, 2002 No. 165-FL), which establish the equality of the languages of the peoples of the Russian Federation and guarantees all its peoples, regardless of their quantity, equal rights to the preservation and comprehensive development of their native language, freedom of choice and use the language of communication, as well as guarantees for the use of the native language, free choice of the language of communication, education, training and creativity, regardless of its origin, social and property status, race and nationality, gender, education, attitude to religion and place of residence. Republics and other subjects of the Federation, as well as areas of compact residence of the population, have the right to establish their state languages in accordance with the "Constitution" of the Russian Federation.

As another example of the methods for resolving an ethnopolitical conflict, we propose the following forms of methods of state structure: autonomization (the Basque country, Catalonia and Galicia as part of Spain, South Tyrol as part of Italy, Scotland and Wales as part of the United Kingdom), a federal model (Russian Federation, Germany, India, Canada and Switzerland).

The fourth feature of the socialization of the younger generation as gaining experience in overcoming the consequences of an ethnopolitical conflict can be defined as the presence of authoritative leaders ("Father of the Nation") and their advisers, or persons close to the leader, both positively influencing the adjustment of the conflict, and negatively - through attempts at personal revenge and self-affirmation in the politics of the region and the world, the realization of their personal and political ambitions. These leaders become the ideals and standards of youth, young people want to be like them externally and internally (Mahatma Gandhi, Mustafa Kemal Ataturk, Charles de Gaulle, Mao Zedong, Fidel Castro, Hugo Chavez, V.V. Putin).

The fifth feature of the socialization of the younger generation as gaining experience in overcoming the consequences of an ethnopolitical conflict is taking into account various ethnosocial and ethnopsychological characteristics of a people, nation or ethnos. As an example, we can offer the features of the southern and northern peoples, peoples of the East, ethnic groups of the Caucasus (S.G. Elizarov, I.N. Narykova, O.I. Orlova 
[27, p.69]). A feature of the southern peoples in comparison with the northern ones can be increased militancy, intemperance, etc. This is expressed in various non-verbal communication - aculesics, kinesics, tactile behavior, chronology, proxemics, sensing, paraverbal communication (A.A. Bodalev, V.A. Labunskaya).

The sixth feature of the socialization of the younger generation as gaining experience in overcoming the consequences of an ethnopolitical conflict is the "strength" of the ethnic in the self-awareness of the people, as it is determined by the people themselves. Thus, with the development of society as a whole, the ethnic self-awareness of the people grows and as a result, there is an activation of national movements and an increase in the desire of peoples to improve their status. Furthermore, representatives of the people may leave their native territory (historical homeland), but at the same time remain fighters for their national or ethnic identity due to the impossibility of integrating into another culture (no such an opportunity), due to the preservation of their language, culture, traditions and customs (it's easier to survive in a foreign country), etc. An example is the Arab communities in European countries, who have lived for more than fifty years in these countries and have grown up for 2-3 generations, but have not been assimilated into the ethnic space of a European country - they preserve and actively use their language, culture, traditions, customs, not only in places of compact residence, but throughout Europe, demanding the recognition of the native language as the state language, their customs - as European ones, etc. This results in ethnic and religious conflicts on the territory of European countries (France, Belgium, Germany) ([24, p.194]).

This allows us to formulate the seventh feature of socialization of the younger generation as gaining experience in overcoming the consequences of an ethnopolitical conflict, which consists in the inadmissibility and impossibility of the "transfer" of the regional conflict by the young generation to another territory, to another region and at another time. An antiexample is the transfer of conflicts from the countries of North Africa and the Middle East to Europe, from the second half of the twentieth century to the zero-tenth years of the twenty-first century.

It is also important to highlight the eighth feature of the socialization of the younger generation as gaining experience in overcoming the consequences of an ethnopolitical conflict, which should not cover not only the direct participants in the conflict, but also future generations - their children, grandchildren, and other categories of the population - neighbors in the region, other ethnic groups. Nevertheless, the consequences of the conflict in the form of injuries are both physical and mental (post-traumatic impact on a person, as a psychotrauma, since people who have experienced a conflict situation, especially in an armed form - war, act as combatants - people who are directly involved in hostilities, although not in the armed forces of one of the parties to the armed conflict) (O.V. Moskalenko [28, p.12]).

Moreover, it is significant that clashes are passed from generation to generation in the form of oral folk art, in which glorifiy their own national defenders, and, conversely, attribute negative external and internal qualities to opponents.

Some researchers (S. Kurtenbach [29, p.8]) consider the emerging violence of the post-war youth as a response to the conflict in the region and, as a result, the formation of a disrespectful attitude towards a more mature society as having no resources to prevent this conflict and more beneficial for the ethnos settlement (on the example of Guatemala and Cambodia). It is the various options for the end of the war, reconstruction after the end of the war that are defined, in the author's opinion, as the main intermediate variables that explain the differences in youth violence in the study of conflicts.

At the same time, mass psychotraumatism of the civilian population as a result of wars and various disasters in the world has been noted among all ethnic groups, without exception, since antiquity $[30$, p.6].

\section{CONCLUSION}

The features of socialization of the younger generation in a post-conflict society revealed in the study as gaining experience in overcoming the consequences of an ethnopolitical conflict allow us to organize social and psychological activities to minimize the consequences of an ethnopolitical conflict for the younger generation.

This program should include measures to form the position of the younger generation on the peaceful settlement of any conflict, including ethno-political, interethnic, interpersonal, as well as a culture of peace and peace-building. This can help young people with interpersonal relationships in society.

The next part should be classes on the genesis of both the conflict situation itself and the subjects of the conflict and the countries, peoples, surrounding this conflict, etc.

It is important to show the young generation individual ways and forms of searching for conditions for entogenesis of oneself as one of the representatives of the people that are part of the national composition of the country, and understanding their role in a multinational state. In this direction, it is important to form in the younger generation the position of the subject of the development of self-awareness and ethno-consciousness without hope for others.

An effective help in this aspect can be reliance on the leaders of the nation, who positively influence the 
settlement of the conflict, the formation of a culture of peace among the population of the country. It is also possible to work with the leaders who negatively influence these processes, but at the same time conducting a critical analysis of their activities in conflict genesis.

In the proposed work, it is important to acquaint the young generation of the ethnos with the various ethnosocial and ethnopsychological characteristics of the people, nation or ethnos, the "power" of the ethnic in selfconsciousness, the history and traditions of the ethnos, while forming the position of not moving the regional conflict to another territory, to another region and to another time, which can help the younger generation and in interpersonal communication in society not to shift the conflict to others, not to assign responsibility to others, to be an actor and motivator of their actions.

It is important for the younger generation to form an objective picture of the ethnopolitical conflict and be adequately conveyed to the present and future members of society, without continuing to incite mistrust and hatred of other ethnic groups with which today there is either a conflict or a post-conflict situation.

In this we see the practical orientation of our research.

\section{FUNDING}

The research was carried out with the financial support of the RFBR within the RFBR research project "Experience of overcoming difficult life situations by the older generation as a factor of youth resilience in the period of the post-war state of society", project No. 20513-07004.

\section{REFERENCES}

[1] P.A. Tsygankov Theory of International Relations, M.: Gardariki, 2003, 590 p.

[2] A.Ya. Antsupov, A.I. Shipilov Conflictology, M.: UNITY, 2000, 551 p.

[3] V.I. Blishchenko, M.M. Solntseva. Crises and conflicts in the post-Soviet space, M.: Aspect Press. 2014, 303 p.

[4] V.V. Amelin Ethnopolitical conflicts: types and forms of manifestation, regional features, Credo new 1 (1997) 23-27. Retrieved from: https://unis.shpl.ru/Pages/Search/BookCard.aspx?i $\mathrm{d}=3576528$

[5] V.A. Moskalenko, Impact of the consequences of regional conflicts in the Middle East on the policy of the Republic of Turkey, Ed. A.V. Shtanova, M.: Nestor-History, 2018, 208 p.
[6] M.M. Lebedeva, Global politics, M.: Aspect Press. 2007, 348 p.

[7] V.A. Moskalenko, The role of the Turkish Republic in solving regional conflicts in international relations, M.: Publishing house Nestor-History, 2016, 101 p.

[8] F. Charton-Vachet, C. Lombart, New conceptual and operational approach to the link between individual and region: regional belonging, Recherche et Applications en Marketing Vol. 30(1) (2015) 50-75.

[9] Shale Horowitz, Explaining Post-Soviet Ethnic Conflicts: Using Regime Type to Discern the Impact and Relative Importance of Objective Antecedents, Nationalities Papers, Vol. 29, Iss. 4, pp. 633-660. DOI: https://doi.org/10.1080/00905990120102129

[10] T. Shelling, Conflict strategy, M.: IRISEN, Socium. 2016, 367 p.

[11] E.N. Ryadinskaya, Features of psychological states of a person living in an armed conflict zone in the context of transformations of life-meaning strategies in the post-conflict period, Psychology and Law. Vol. 6 Iss. 4 (2016) 196-208. DOI: https://doi.org/10.17759/psylaw.2016060418

[12] I.A. Alikin, M.I. Alikin, N.V. Lukyanchenko, Relationship between students' vitality and the attitude of their parents towards them, Psychological Science and Education Vol. 25 Iss. 3 (2020) 75-89. DOI: https://doi.org/10.17759/pse.2020250307

[13] L.M. Mitina, G.V. Mitin, Psychological analysis of the problem of marginalism, procrastination, learned helplessness as barriers to personal and professional development of a person, Psychological Science and Education Vol. 25 Iss. 3 (2020) 90-100. DOI: https://doi.org/10.17759/pse.2020250308

[14] M. Antonsich, E. Holland, Territorial attachment in the era of globalization: the case of Western Europe, European Urban and Regional Studies Vol. 21(2) (2014) 206-221.

[15] C. Zuniga, R. Asun, Social identity and intergroup discrimination. An inevitable relationship? The case of regional identities in Chile, Revista de psicologia social Vol. 25(2) (2010) 215-230.

[16] L.V. Luchsheva, Modern concepts of the causes of ethnic conflicts, Bulletin of Economics, Law and Sociology: Publishing house: LLC "Expert 16 (Kazan)" 1 (2015) 206-209. Retrieved from: https://elibrary.ru/item.asp?id=23272791 
[17] A.A. Sultygov, Solving Ethnopolitical Conflicts in Russia: Historical Experience and Modernity, Bulletin of Moscow University. Series 12. Political Sciences 2005, pp. 69-94. Retrieved from: https://elibrary.ru/item.asp?id=11750132

[18] N.M. Borisova, I.V. Shapovalenko, Personal determinants of coping behavior in middle age, Psychological and pedagogical research. Vol. 10 Iss. 3 (2018) 115-125. DOI: https://doi.org/10.17759/psyedu.2018100310

[19] V.V. Bartsalkina, L.V. Volkova, I. Yu. Kulagina, Features of the value-semantic sphere in experiencing a difficult life situation in maturity, Consultative psychology and psychotherapy Vol. 27 Iss. 2 (2019) 69-81. DOI: https://doi.org/10.17759/cpp.2019270205

[20] E.G. Siukaeva, L.M. Khabaeva, M.Z. Gazzaeva, N.M. Gazzaeva, I.V. Abaeva, E.P. Gioeva, Social identity and professional development of youth in South Ossetia. Tskhinval: YuOGU, 2020, 290s.

[21] O. Ghimbulut, A. Opre, Assessing Resilience Using Mixed Methods: Youth Resilience Measure, Procedia - Social and Behavioral Sciences Vol. 78. (2013) 310-314. Retrieved from: http://www.sciencedirect.com/science/article/pii/S1 $\underline{877042813008707}$

[22] K. Homa, The effect of social support on resilience, ProQuest Dissertations and Theses, 2012, 51 p. Retrieved from: http://search.proquest.com/docview/1038969704?a c countid=35419. (1038969704)

[23] S.R. Maddi, D.M. Khoshaba, Hardiness and mental health // Journal of Personality Assessment Vol. 63 (1994) 265-274.

[24] E. Schubach, J. Zimmermann, P. Noack et al. Me, Myself, and Mobility: The Relevance of Region for Young Adults' Identity Development, European journal of personality Vol. 30(2) (2016) 189-200.

[25] L.A. Maksimova, R.A. Valiev, N.B. Ruzhentseva, T.V. Valieva, Regional identity in adolescence as a marker of personal connection with the territory of residence, Psychological Science and Education Vol. 24 Iss. 2 (2019) 82-92. DOI: https://doi.org/10.17759/pse.2019240208

[26] O.E. Khukhlaev, V.M. Minazova, O.S. Pavlova, E.V. Zykov, Social identity and ethno-national attitudes of student youth in Chechnya, Social psychology and society Vol. 6 Iss. 4 (2015) 23-40. DOI: $\underline{\text { https://doi.org/10.17759/ sps.2015060403 }}$

[27] S.G. Elizarov, I.N. Narykova, O.I. Orlova, A teenager in a difficult life situation: the possibilities of post-rehabilitation support, Bulletin of practical psychology of education Vol. 16 Iss. 2 (2019) 6874. DOI: https://doi.org/10.17759/bppe.2019160210

[28] O.V. Moskalenko, Human psychology in a pandemic situation, M.: Egorievsk branch of the Moscow State Pedagogical University, 2020, 177 p.

[29] S. Kurtenbach, Postwar Youth Violence: A Mirror of the Relationship between Youth and Adult Society, GIGA, Working Paper, Iss. 199, July 2012, 29 p. DOI: http://dx.doi.org/10.2139/ssrn.2143125

[30] The Psychological impact of war trauma on civilians: An intern. perspective, Ed. by Stanley Krippner a. Teresa M. McIntyre; Forew. by Stevan E. Hobfoll; Afterw. by Jeanne Achterberg. Westport (Conn.): Praeger, 2003, 327 p. 